\title{
PROFMAT: UM PROGRAMA PIONEIRO
}

\author{
PROFMAT: A PIONEER PROGRAM
}

Vanderlei Horita ${ }^{1}$

RESUMO: O Profmat é o maior programa de pós-graduação do Brasil. A rede possui mais de 80 instituições associadas ofertando vagas em cerca de 100 de suas unidades acadêmicas, e está presente em todas as unidades federativas do país. Até meados de 2021, o Programa formou mais de 6 mil mestres. Nas próximas páginas apresentamos um pouco da sua história e da estrutura do Programa que inspirou mais de uma dezena de outras áreas a criarem programas para qualificação de professores do ensino básico.

PALAVRAS-CHAVE: Pioneirismo. Qualificação de professores. Educação básica.

ABSTRACT: Profmat is the largest graduate program in Brazil. The network has more than 80 institutions offering places in around 100 of its academic units, and is present in all federative units in the country. By mid2021, the Program had graduated more than 6,000 Master's degrees. We present a piece of its history and the structure of the program that inspired more than a dozen other areas to create similar programs for qualification of primary and secondary teachers.

KEYWORDS: Pioneering. Teacher qualification. Primary and secondary education.

\section{Introdução}

Neste momento em que o país retoma as atividades e a convivência social interrompidas pela pandemia causada pelo SARS-CoV-2, apresenta-se um enorme desafio em todos os níveis da educação. Durante a pandemia, o professor, tão desvalorizado ao longo das últimas décadas, teve o valor do seu trabalho trazido à luz. Todo progresso da revolução digital mostrou-se insuficiente no processo ensino-aprendizagem sem as escolas e seus professores e funcionários. Em que pese todo o aprendizado e experiências adquiridas pelo professor neste período, devemos nos render à constatação de que as melhores ferramentas tecnológicas de ensino remoto não alcançam os resultados de um bom professor na sala de aula. Ressaltou-se ainda mais o papel central do professor na educação. Muitas das práticas desenvolvidas nesse período deverão ser incorporadas na volta presencial. É preciso valorizar esses profissionais.

Sem uma comunicação transparente com a sociedade e sem planejamento, o Brasil foi um dos países que ficou mais tempo com as escolas fechadas. A educação não foi

\footnotetext{
1 Universidade Estadual Paulista. E-mail: vhorita@gmail.com

(i) https://orcid.org/0000-0002-9304-0655

- Informações completas da obra no final do artigo
} 
tratada como prioridade e sentiremos os efeitos por décadas, por gerações. É inadiável investir maciçamente na educação, e aqui defenderei que o investimento na matemática deve ser tratado com especial atenção.

Note que foi utilizada a palavra investimento e não gasto. Segundo um estudo de 2010 no Reino Unido, encomendado pela agência EPSRC (Engineering and Physical Sciences Research Council), a matemática gera diretamente $10 \%$ do total de empregos e $16 \%$ do PIB dos países. Além disso, trabalhadores bem capacitados em matemática contribuem para o desenvolvimento de processos e produtos de ponta em todas as áreas. Um agricultor, um pecuarista ou um médico com bons conhecimentos de matemática pode ter um ganho de eficiência enorme ao conectar mais conhecimentos utilizando raciocínios lógico e dedutivos.

Em 2007, a Coordenação de Aperfeiçoamento de Pessoal de Nível Superior (Capes) recebeu a missão de formular políticas públicas para qualificação de professores de ensino básico. Até então, em seus 56 anos de existência, a Capes alcançou um alto grau de reconhecimento pelo sistema de pós-graduação ter alcançado os níveis de excelência na formação de pesquisadores e professores do ensino superior.

Nesse contexto, o Presidente da Capes em 2010, Prof. Jorge Almeida Guimarães, provocou a comunidade matemática, por meio da Sociedade Brasileira de Matemática (SBM) sob a liderança de Hilário Alencar e Marcelo Viana, um programa de mestrado voltado à qualificação do professor de matemática do ensino básico. Eles idealizaram e lideraram a criação desse mestrado, com denominação Programa de Mestrado Profissional em Matemática em Rede Nacional (Profmat), cuja sua aula inaugural teve lugar na sede do Instituto de Matemática Pura e Aplicada (IMPA), no Rio de Janeiro, em pleno sábado, no dia 2 de abril de 2011, às 11h. Essa aula inaugural contou com as presenças dos professores Jorge Almeida Guimarães (Presidente da Capes), Elon Lages Lima (Coordenador do Profmat), Cesar Camacho (Diretor do IMPA), Celso Costa (Diretor de Educação a Distância da Capes), Hilário Alencar (Presidente da SBM), Marcelo Viana (Presidente do Conselho Gestor do Profmat e Vice-presidente da SBM), Jacob Palis (Presidente da Academia Brasileira de Ciências), e foi transmitida ao vivo via internet para todas as instituições associadas.

O Profmat é o maior programa de pós-graduação do país e um dos maiores, se não o maior, do mundo. A rede conta com mais de 80 instituições associadas ofertando vagas 
em cerca de 100 de suas unidades acadêmicas, alcançando todos os Estados e o Distrito Federal. Até meados de 2021, o Programa formou mais de 6 mil mestres.

Convidamos o leitor a conhecer nas próximas páginas um pouco da história e da estrutura do programa que inspirou mais de uma dezena de outras áreas a criarem programas para qualificação de professores do ensino básico.

\section{Contextualização}

Uma questão natural é: Por que uma sociedade científica, a SBM, foi o meio que a Capes utilizou para induzir um programa de pós-graduação para melhoria da formação do professor? A pesquisa em Matemática do Brasil, a partir de 2015, foi responsável por cerca de $2,37 \%$ do total da produção científica mundial na área. A população brasileira em 2020 representava cerca de $2,71 \%$ da população global. Numericamente, a comunidade científica Matemática brasileira produz aproximadamente à proporção da população do país.

Qual é a qualidade dessa produção científica? Um bom indicador para responder a essa pergunta é a estratificação em grupos dos países da União Internacional de Matemática (IMU - sigla em inglês), que congrega os países representativos na área. $\mathrm{O}$ Brasil em 2018 ascendeu ao Grupo V, que representa o grupo dos países em estágios mais avançados no desenvolvimento na área de Matemática. Formam esse grupo: Alemanha, Brasil, Canadá, China, Estados Unidos, França, Israel, Itália, Japão, Reino Unido e Rússia. O país está no grupo de 11 países no topo dos melhores da IMU, que conta com 87 países membros.

E sobre o ensino de matemática no país? Como parâmetro de comparação entre países, o Programa Internacional de Avaliação de Estudantes (Pisa) realizado pela Organização para a Cooperação e Desenvolvimento Econômico (OCDE) é um dos principais referenciais internacionais de desempenho de estudantes, ele é realizado a cada três anos. São avaliados do desempenho dos estudantes de 15 anos de idade em três domínios: Leitura, Matemática e Ciências. Os resultados permitem que os países avaliem os conhecimentos e habilidades de seus estudantes em comparação com os de outros países. O Brasil participa do Pisa desde sua primeira edição em 2000. Na última edição, em 2018, entre os 79 países e regiões que participaram do Pisa, o país ficou entre os 10 últimos em desempenho em Matemática. 


\section{ENSIN@UFMS 2021}

ISSN 2525-7056

Muitas perguntas passam pela nossa cabeça quando olhamos o abismo entre a pesquisa científica e o ensino de Matemática. Mas, por onde começar? A nossa resposta é qualificando e valorizando os professores.

Essa resposta nos leva a outras perguntas e que levam a outras mais. A transformação e melhoria da educação depende de várias ações como maior domínio do conteúdo pelo professor do que será ensinado, melhores práticas didáticas conectadas com a realidade dos estudantes, condições de trabalho adequadas, salários compatíveis, por exemplo. Cada indivíduo, grupo, e comunidade pode dar a sua contribuição. O Profmat é uma das ações abraçadas pela comunidade matemática.

O que os matemáticos mais gostam de fazer, é resolver problemas, quanto mais difíceis, mais desafiadores são. A melhoria da educação básica do Brasil, particularmente do Ensino de Matemática, certamente é um dos problemas mais complexos que a comunidade matemática vem buscando soluções. O Profmat não é a primeira iniciativa da comunidade nesta direção. Somente para citar duas das mais recentes, temos as Olimpíadas Brasileiras de Matemática das Escolas Públicas (OBMEP) e o Programa de Aperfeiçoamento para Professores de Matemática do Ensino Médio (PAPMEM), este último inspirador do Profmat. Ademais, há uma farta e profícua produção de material didático na área de Matemática, a maioria disponibilizada gratuitamente aos interessados.

\section{O Profmat}

O Profmat é um programa pioneiro na qualificação de professores do ensino básico em nível de mestrado. O objetivo principal do Profmat é proporcionar formação matemática aprofundada relevante ao exercício da docência no Ensino Básico, visando dar ao egresso qualificação certificada para o exercício da profissão de professor de Matemática. Para atingi-lo, o programa fundamenta-se nas seguintes diretrizes:

i) Executar um processo de formação complementar em matemática, baseado na estrutura curricular da Base Nacional Comum Curricular (BNCC), que promova o domínio dos conteúdos apropriados, da forma de pensar e das estratégias de resolução de problemas característicos da matemática.

ii) Promover uma articulação eficaz entre conhecimentos e práticas das ciências matemáticas e do ensino básico, direcionada aos objetivos da educação básica. 


\section{ENSIN@UFMS 2021}

ISSN 2525-7056

iii) Estimular e promover a independência do professor, fornecendo-Ihe instrumentos para busca por conhecimento e desenvolvimento profissional de forma autônoma, crítica e permanente.

iv) Incentivar a pesquisa e produção de materiais (artigos, livros, produtos técnicotecnológicos, etc.) e práticas pedagógicas inovadoras para o enriquecimento do processo de ensino e aprendizagem de Matemática na escola.

Espera-se que o egresso do Profmat tenha um pleno domínio do conteúdo específico de Matemática, inclusive de suas aplicações mais imediatas, bem como uma noção da evolução histórica dos principais temas que constam na BNCC da Educação Básica.

São verificados impactos relevantes nas práticas em sala de aula e nas escolas em que egressos do Profmat atuam como criação de laboratórios de ensino e ambientes de aprendizagem; maior estruturação dos conteúdos ministrados; ampliação do uso de ferramentas pedagógicas e tecnológicas, muitas delas desconhecidas antes de ingressar Programa, tais como GeoGebra e outros softwares matemáticos, jogos educacionais (gameficação), dobraduras e robótica; formação de turmas para treinamento para olimpíadas de matemática e outras olimpíadas científicas; uso maior de contextualizações concretas dos conteúdos, com focagem na compreensão no lugar da memorização dos conteúdos; maior autonomia em sala de aula, transformando livros-textos e apostilas como fio norteador das atividades no lugar de fontes exclusivas de conhecimento; egressos atuam como multiplicadores junto a professores do ensino básico; desenvolvimento de ações voltadas à portadores de necessidade especiais no ensino de matemática; melhoria na prática pedagógica, tanto no campo cognitivo quanto no metodológico, entre outros.

O Profmat propiciou a professores das instituições associadas a possibilidade de atuar na qualificação do professor da educação básica, utilizando recursos humanos altamente qualificados em prol da melhoria do ensino de matemática. A formação do corpo docente do programa é nas áreas de Matemática, Educação Matemática, Educação e áreas afins, com experiência em matemática. Vários professores e egressos do Profmat participam ativamente na produção de materiais didáticos. Um exemplo é o projeto "Livro Aberto de Matemática"2, uma iniciativa da Olimpíada Brasileira de Matemática das Escolas Públicas (OBMEP), do Instituto de Matemática Pura e Aplicada (IMPA). O projeto é um

\footnotetext{
2 Disponível em: https://umlivroaberto.org/
} 
esforço de professores para produzir coleções de livros didáticos de Matemática para a Educação Básica de forma colaborativa e com licença aberta (Creative Commons). 0 conteúdo de cada livro é determinado pela BNCC e complementado com tópicos extras.

\section{Um programa em rede}

O Profmat é um programa em rede formando mestres em todo país. Para assegurar que os alunos de todas as partes recebam uma formação de qualidade e com um padrão mínimo de excelência, levando-se em conta as regionalidades, a rede está articulada pelo:

a) Exame Nacional de Acesso (ENA), processo seletivo com oferta unificada, elaborado por comissão designada pela Comissão Acadêmica Nacional com aplicação e correção sob responsabilidade das coordenações institucionais.

b) Exame Nacional de Qualificação (ENQ), constituído por uma prova discursiva sobre os conteúdos das disciplinas básicas, elaborada e corrigida por comissões designadas pela Coordenação Nacional e aplicada pelas coordenações das instituições associadas. A aprovação no ENQ é requisito obrigatório para obtenção do título de mestre.

c) Livros-textos da Coleção PROFMAT, utilizados nas disciplinas do Programa. A coleção foi criada pela SBM para o Programa. Atualmente, a coleção conta com 18 títulos.

d) Reuniões de coordenadores, pelo menos uma vez ao ano, oportunidades em que são debatidas questões acadêmicas e administrativas do programa.

e) Sistema de Controle Acadêmico (SCA), sistema nacional informatizado que permite o gerenciamento acadêmico do Profmat.

O ENQ e a Coleção PROFMAT asseguram uma formação básica uniforme do conteúdo das disciplinas em toda a rede. A Coleção PROFMAT da SBM conta com 18 títulos que compõe a bibliografia básica de disciplinas. Foram produzidas videoaulas de 8 disciplinas, que abrangem os conteúdos de todas as disciplinas básicas. Os livros e as videoaulas são produzidos especificamente para o Programa, dando uniformidade dos conteúdos das disciplinas e maior autonomia aos discentes.

\section{Trabalho de Conclusão}

Para a obtenção do título, é necessária a apresentação de um trabalho de conclusão, com temas específicos pertinentes ao currículo de Matemática da Educação Básica e impacto na prática didática em sala de aula, atendendo aos objetivos do Programa, 
que pode ser apresentado em diferentes formatos, tais como dissertação, revisão sistemática e aprofundada da literatura, artigo, patente, registros de propriedade intelectual, projetos técnicos, publicações tecnológicas; desenvolvimento de aplicativos, de materiais didáticos e instrucionais e de produtos, processos e técnicas; produção de programas de mídia, editoria, relatórios finais de pesquisa, softwares, projeto de aplicação ou adequação tecnológica, protótipos para desenvolvimento ou produção de instrumentos, equipamentos e kits, projetos de inovação tecnológica, sem prejuízo de outros formatos. Independente do formato apresentado, é obrigatório que o trabalho de conclusão final do Profmat tenha um texto formalmente redigido. Os trabalhos de conclusão de curso estão disponíveis em http://www.profmat-sbm.org.br/dissertacoes.

\section{A formação não acaba na titulação}

A evolução e inovação dos conhecimentos e das práticas pedagógicas estão em permanente avanço. Para complementar a formação e estreitar a relação entre os egressos do Profmat, e criar um espaço para discussões sobre a educação básica, a SBM organizou em 2013 o Simpósio Nacional da Formação do Professor de Matemática. Nesta ocasião, foi criada a Associação Nacional de Professores de Matemática - ANPMat, associação com ampla participação de egressos do Profmat em sua diretoria, e vem dando continuidade à organização dos simpósios, nacionais e regionais, que até o final de 2021 totalizarão 17 edições.

Os simpósios são eventos acadêmicos organizados por professores da Educação Básica para professores da Educação Básica. Além dos egressos e discentes do Profmat, eles contam com a participação de professores de educação básica, de institutos federais, formadores de professores, licenciandos em Matemática e alunos do Ensino Médio, oriundos de todas as regiões do país. As programações consistem de palestras, minicursos, oficinas, grupos de trabalho, mesas redondas e sessão de pôsteres. As palestras versam sobre formação e qualificação profissional e temas relacionados ao ensino de Matemática. Os minicursos e oficinas tem por objetivo difundir pesquisas sobre diversos temas relacionados à Matemática e apresentam novas propostas para seu ensino, contribuindo para a qualificação de professores e demais profissionais da área.

As atividades da ANPMat vão muito além dos simpósios. Vale a pena visitar a página da associação http://anpmat.sbm.org.br e se associar. 


\section{Um pouco da história}

O Profmat é oferecido por Instituições de Ensino Superior associadas em uma Rede Nacional, no âmbito do Sistema Universidade Aberta do Brasil (UAB). É coordenado pela Comissão Acadêmica Nacional, que opera sob a égide da Diretoria da SBM, com apoio do IMPA.

O Profmat foi recomendado pelo Conselho Técnico-Científico da Educação Superior da Capes (CTC-ES) em 08/11/2010, tendo sido homologado pela Portaria no 1325 do Ministério da Educação de 22/09/2011. A aula inaugural ocorreu no dia 02/04/2011 com a presença de várias autoridades. A Capes financia o Profmat através do Programas de Mestrado Profissional para Qualificação de Professores da Rede Pública de Educação Básica (ProEB).

Para enfrentar o desafio que se apresentava, era necessário um programa que, desde sua criação, tivesse grande abrangência nacional ofertando um grande número de vagas, compatível com o tamanho do desafio. Na criação, a rede contava com 48 instituições associadas ofertando vagas em 54 de seus campi. Desde 2012, o Profmat está presente em todos os 26 Estados e no Distrito Federal, possuindo alunos matriculados em mais de 100 campi das instituições associadas. Até 2021, foram ofertadas 15.505 vagas, veja tabela abaixo. Em 2020, em razão do cancelamento determinado pela Diretoria de Educação à Distância (DED) da Capes do edital do processo seletivo autorizado pela Diretoria em julho de 2019, da política da DED de início das turmas dos programas financiados pelo ProEB em agosto de cada ano e do posterior recrudescimento da pandemia da COVID-19, não houve ingresso no programa nesse ano.

Tabela 1. Vagas ofertadas

\begin{tabular}{|c|c|c|c|}
\hline Ano & $\begin{array}{c}\text { Instituições } \\
\text { Associadas }\end{array}$ & Campi & $\begin{array}{c}\text { Vagas } \\
\text { ofertadas }\end{array}$ \\
\hline 2011 & 48 & 54 & 1.192 \\
\hline 2012 & 57 & 67 & 1.575 \\
\hline 2013 & 58 & 71 & 1.570 \\
\hline 2014 & 57 & 69 & 1.500 \\
\hline 2015 & 65 & 80 & 1.575 \\
\hline 2016 & 61 & 75 & 1.470 \\
\hline 2017 & 69 & 79 & 1.595 \\
\hline 2018 & 74 & 79 & 1.795 \\
\hline 2019 & 75 & 96 & 1.833 \\
\hline 2021 & 73 & 91 & 1.400 \\
\hline
\end{tabular}

Fonte: Sistema de Controle Acadêmico do Profmat. 
Para o Profmat foi criada uma coleção de livros-textos, a Coleção PROFMAT da SBM, relevantes para a formação do professor da Escola Básica, em todos os temas da Matemática, sua prática de ensino, sua história e suas aplicações.

Em 2020, em uma ação da Secretaria de Educação do Estado do Ceará para qualificação do seu corpo docente, foi firmado um Termo de Cooperação Técnica entre a Secretaria, a SBM e as instituições associadas do Estado - Universidade Federal do Ceará (UFC), Universidade Estadual do Ceará (UECE), Universidade da Integração Internacional da Lusofonia Afro-Brasileira (UNILAB), Universidade Regional do Cariri (URCA) e Universidade Federal do Cariri (UFCA), para o oferecimento de vagas do Profmat para os professores em exercício da docência de Matemática da rede púbica estadual. Esta cooperação constitui uma etapa das ações do Programa Cientista-Chefe em Educação, que conta com apoio da Fundação Cearense de Apoio ao Desenvolvimento Científico e Tecnológico (FUNCAP).

\section{Impactos}

Como consequência da formação recebida, os egressos do Profmat relatam com satisfação os conhecimentos adquiridos e o impacto que o curso teve em suas práticas didáticas na sala de aula. Esses relatos são reforçados pelos diretores de escolas onde esses egressos atuam através de enquete em Spineti Consultoria, Ensino e Pesquisa (2017). Os relatos mais frequentes são:
a) melhoria na capacidade de argumentação e de raciocínio lógico dedutivo;
b) maior segurança, motivação e desenvoltura em sala de aula;
c) uso de exemplos mais práticos e concretos nas aulas;
d) as abordagens dos conteúdos ficaram facilitadas e conectadas ao dia a dia, com linguagem mais acessível aos alunos.

Muitos dos materiais produzidos por egressos são de forma pouco estruturada, em canais de Youtube, blogs, grupos de redes sociais e troca de experiências entre professores, cadernos de atividades, livros paradidáticos, livros digitais, jogos computacionais, apostilas e aplicativos.

Vários egressos colaboram na preparação dos alunos interessados em participar de olimpíadas como a Olimpíada Brasileira de Matemática das Escolas Públicas (OBMEP) e 
a Olimpíada Brasileira de Matemática (OBM) e de outras olimpíadas matemáticas e de outras áreas. Há participação ativa de egressos em programas da OBMEP, tais como PICOBMEP, OBMEP na escola e POTI (Polo Olímpico de Treinamento Intensivo) em conjunto com professores universitário. As olimpíadas são exemplos de abertura de espaços de maior interação entre a escola básica e a universidade propiciado pelo Profmat.

\section{O Profmat e o PNE}

O Profmat vem ao encontro do Plano Nacional de Educação - PNE, Lei № 13.005, de 25/06/2014, que coloca em sua Meta 16: formar, em nível de pós-graduação, 50\% (cinquenta por cento) dos professores da Educação Básica, até o último ano de vigência deste PNE, e garantir a todos(as) os(as) profissionais da Educação Básica formação continuada em sua área de atuação, considerando as necessidades, demandas e contextualizações dos sistemas de ensino. Além disso, o Profmat também atende as metas 14, 17 e 18 do PNE, que tratam respectivamente, elevar o número de matrículas na pósgraduação stricto sensu; valorização do professor; e plano de carreira.

\section{Mais impactos}

São organizados vários eventos pelas instituições associadas voltados aos alunos e professores do Profmat e da licenciatura que são abertos ao público geral, como encontros, seminários, ciclos de debate, semanas de curso, seminários e webinários. Como mencionado anteriormente, a ANPMat conta com egressos e professor do Profmat em sua diretoria e nas secretarias regionais.

Há melhoria no índice IDEB das escolas onde professores formados pelo Profmat atuam, aumento nas notas dos alunos no ENEM, aumento no número de alunos medalhistas em olimpíadas de matemática. Muitos egressos levam seus alunos para visitas às universidades tendo como consequência o incentivo ao ingresso no ensino superior.

Com relação à carreira docente, verifica-se melhorias como progressão funcional e salarial, aprovação em concursos em outras escolas públicas, participação em conselhos escolares, organização da área de Matemática na escola que trabalham.

Os discentes titulados no Profmat tem assumido cargos nas Secretarias Regionais de Educação, ocupando espaços nas representações da categoria profissional, assumido cargos públicos (incluindo o de vereador) em suas cidades, além de reproduzirem eventos, 


\section{ENSIN@UFMS 2021}

ISSN 2525-7056

feiras e palestras sobre a matemática, aumentando e melhorando a participação deles no ambiente escolar.

\section{Desafios}

O longo período de fechamento das escolas causado pela pandemia prejudicou enormemente o ensino de crianças e adolescentes, que já não apresentava boas avaliações. O primeiro grande desafio que se apresenta é diagnosticar a etapa de aprendizagem em que os alunos estão no retorno às escolas e traçar estratégias para mitigar o problema. A principal contribuição do Profmat será na qualificação dos professores de Matemática dentro dos objetivos do Programa. Neste cenário, os principais desafios são:

- Estruturar e fomentar a geração de produtos oriundos dos trabalhos de conclusão que contribuam para atividades em sala de aula.

- Aumentar o compartilhamento dos conhecimentos e das inovações pedagógicas e tecnológicas para o ensino de Matemática advindos do programa.

- Interiorizar a oferta de vagas para que professores de regiões distantes de grandes centros possam ter acesso ao programa.

- Dar continuidade e aperfeiçoamento do monitoramento dos indicadores do Sistema de Avaliação da Educação Básica através do Sistema Nacional de Avaliação da Educação Básica (SAEB) e da Prova Brasil das escolas públicas.

- A ampliação e atualização do quantitativo de videoaulas e de textos para Coleção PROFMAT, com atenção especial para a nova BNCC.

- Utilizar o potencial dos titulados em formações e cursos de níveis intermediários entre a graduação e o mestrado - especialização, aperfeiçoamento e extensão. A formação recebida no Profmat e a experiência prática em sala de aula, torna o egresso altamente capacitado em multiplicar suas competências, seja aos que não almejam cursar um mestrado, seja para preparação para ingressar no Profmat.

- Oferecer formação mais avançada seguindo o perfil do Profmat. Com mais de 6 mil titulados, formou-se um grupo numeroso de professores capacitados e interessados em novos conhecimentos. É natural canalizar esse anseio na estruturação de um programa de doutorado. 


\section{Referências}

CAPES. Avaliação Suplementar Externa do Programa de Mestrado Profissional em Matemática em Rede Nacional (PROFMAT), 2013.

CAPES. Relatórios Coleta/Capes 2013 a 2020.

OMNI3 SOLUÇÕES EM EDUCAÇÃO E COMUNICÃO LTDA. Quem é o Professor de Matemática da Escola Básica? Uma análise quali-quantitativa de perfis de candidatos ao Mestrado Profissional em Matemática em Rede Nacional (PROFMAT), 2013.

SPINETI CONSULTORIA, ENSINO E PESQUISA. PROFMAT: Uma reflexão e alguns resultados, 2017.

SPINETI CONSULTORIA, ENSINO E PESQUISA. PROFMAT: Avaliação de Possíveis Impactos, 2018.

\section{NOTAS}

\section{IDENTIFICAÇÃO DE AUTORIA}

Vanderlei Horita. Doutorado em Matemática pelo Instituto de Matemática Pura e Aplicada (IMPA), PósDoutorado pela Universidade de Toronto e IMPA (2007) e Universidade de Orsay (2015). Foi Primeirosecretario (2011-2013), Vice-presidente (2013-2015) da Sociedade Brasileira de Matemática e Coordenador da Comissão Acadêmica Nacional do Profmat (11/2017 - 08/2021). Atualmente é professor associado da Universidade Estadual Paulista (UNESP), Instituto de Biociências Letras e Ciências Exatas, Departamento de Matemática, São José do Rio Preto, SP, Brasil.

E-mail:vhorita@gmail.com

(D) https://orcid.org/0000-0002-9304-0655

\section{AGRADECIMENTOS}

Não se aplica.

\section{FINANCIAMENTO}

Não se aplica.

\section{CONSENTIMENTO DE USO DE IMAGEM}

Não se aplica.

\section{APROVAÇÃO DE COMITÊ DE ÉTICA EM PESQUISA}

Não se aplica.

\section{LICENÇA DE USO}

Autores mantêm os direitos autorais e concedem à revista ENSIN@ UFMS - ISSN 2525-7056 o direito de primeira publicação, com o trabalho simultaneamente licenciado sob a Licença Creative Commons Attribution (CC BY-NC-SA 4.0), que permite compartilhar e adaptar o trabalho, para fins não comerciais, reconhecendo a autoria do texto e publicação inicial neste periódico, desde que adotem a mesma licença, compartilhar igual.

\section{EDITORES}

Patricia Helena Mirandola Garcia, Eugenia Brunilda Opazo Uribe, Gerson dos Santos Farias.

\section{HISTÓRICO}

Recebido em: 12/10/2021 - Aprovado em: 30/10/2021 - Publicado em: 15/12/2021. 


\section{COMO CITAR}

HORITA, V. Profmat: Um Programa Pioneiro. Revista ENSIN@ UFMS, Três Lagoas, v. 2, número especial, p. 16-28. 2021. 